\title{
Inhibition of Listeria monocytogenes in Fresh Cheese Using Chitosan-Grafted Lactic Acid Packaging
}

\author{
Laura N. Sandoval ${ }^{1}$, Monserrat López ${ }^{1}$, Elizabeth Montes-Díaz ${ }^{1}$, Andres Espadín ${ }^{1}$, \\ Alberto Tecante ${ }^{2}$, Miquel Gimeno ${ }^{2}$ and Keiko Shirai ${ }^{1, *}$ \\ 1 Laboratory of Biopolymers and Pilot Plant of Bioprocessing of Agro-Industrial and Food By-Products, \\ Biotechnology Department, Universidad Autónoma Metropolitana, Av. San Rafael Atlixco No. 186. Col. \\ Vicentina, C.P., 09340 Mexico City, Mexico; shln1990@hotmail.com (L.N.S.); \\ monclopz_qa@hotmail.com (M.L.); godzypotzy@hotmail.com (E.M.-D.); d_andrewriel@hotmail.com (A.E.) \\ 2 Departamento de Alimentos y Biotecnología, Facultad de Química, Universidad Nacional Autónoma de \\ México, 04510 Mexico City, Mexico; tecante@unam.mx (A.T.); mgimeno@unam.mx (M.G.) \\ * Correspondence: smk@xanum.uam.mx; Tel.: +52-555804-49-21; Fax: +52-555804-47-12
}

Academic Editor: Massimiliano Fenice

Received: 13 February 2016; Accepted: 29 March 2016; Published: 8 April 2016

\begin{abstract}
A chitosan from biologically obtained chitin was successfully grafted with D,L-lactic acid (LA) in aqueous media using $p$-toluenesulfonic acid as catalyst to obtain a non-toxic, biodegradable packaging material that was characterized using scanning electron microscopy, water vapor permeability, and relative humidity $(\mathrm{RH})$ losses. Additionally, the grafting in chitosan with LA produced films with improved mechanical properties. This material successfully extended the shelf life of fresh cheese and inhibited the growth of Listeria monocytogenes during 14 days at $4{ }^{\circ} \mathrm{C}$ and $22 \%$ $\mathrm{RH}$, whereby inoculated samples with chitosan- $g$-LA packaging presented full bacterial inhibition. The results were compared to control samples and commercial low-density polyethylene packaging.
\end{abstract}

Keywords: fresh cheese; Listeria monocytogenes; chitosan; grafting; lactic acid

\section{Introduction}

Listeria monocytogenes is a foodborne pathogen that affects mainly the gastrointestinal tract and also potentially causes septicemia, meningitis, encephalitis, spontaneous abortion or stillbirth $[1,2]$. Listeriosis can be a severe disease, particularly among susceptible populations and a leading cause of death by foodborne illness [3-5]. Outbreaks have been strongly associated with cheese consumption. Fresh cheeses are usually protected from contamination by refrigeration and usually packed with paper or shrink-wrapped with polyethylene or polypropylene with potential risk of proliferation of aerobic mesophilic bacteria, coliforms, molds or yeast. Therefore, these cheeses are usually consumed within one month after manufacture with mounting losses of sensory characteristics throughout this period. The most sensitive of these types of products are soft paste unpressed fresh cheeses. They usually have short shelf lives of up to 10 days and rapid perishability owing to their high moisture (45\%-55\%) and low salt contents and neutral $\mathrm{pH}$ (6.0-6.5) [6]. Additionally, when made from raw milk fresh cheese contains a wide variety of microorganisms, which can include human pathogens as L. monocytogenes, which outbreaks in México have been associated with consumption of this type of cheeses [7].

Recent studies in food packaging are tackling these issues and antimicrobial materials with adequate properties have proved successful to reduce the growth of undesirable microorganisms and to preserve cheese qualities, allowing shelf life to be extended while maintaining good product quality and safety [8]. According to the current international regulations, these packaging materials must be innocuous, resistant and not react or alter the chemical, nutritional and sensorial properties of the packaged products. The food industry is focused on the development of non-toxic antimicrobial 
packaging options following the increasing consumer demand for biodegradable and in some cases even edible coatings free of preservatives or potentially toxic chemical additives that can migrate into foods. There has been increasing interest in antimicrobial films because microbial contamination occurs mainly on the cheese surface, which is the primary spoilage source. Films derived from renewable biomass sources and so-called bioplastics, such as chitosan-based films, might be potential alternatives to oil-derived plastics [9]. Chitosan is a non-toxic, renewable, biodegradable and biocompatible polysaccharide mainly composed of repeating glucosamine units. However, chitosan films present poor mechanical properties, which restrict their application for food packaging. As a way to avoid this drawback, grafting with other components can improve its mechanical properties [9]. This study establishes a method for extending the shelf life of fresh cheeses with inhibition of L. monocytogenes by using packaging films of chitosan grafted with D,L-lactic acid (LA).

\section{Results and Discussion}

\subsection{Grafting of LA onto Chitosan}

Table 1 shows the yields, degree of grafting and some properties of the samples. The ChLA-TSA film sample had a thickness of ca. $0.15 \mathrm{~mm}$, which has a positive effect on the WVP $\left(4.2 \times 10^{5} \mathrm{~g} \cdot \mathrm{mm} / \mathrm{m}^{2} \cdot \mathrm{h} \cdot \mathrm{kPa}\right)$ at the studied RH interval (22\%-75\%). Noteworthy, Di Pierro et al. [10] reported WVPs up to $0.0167 \mathrm{~g} \cdot \mathrm{mm} / \mathrm{m}^{2} \cdot \mathrm{h} \cdot \mathrm{kPa}$ which are below the $0.2613 \mathrm{~g} \cdot \mathrm{mm} / \mathrm{m}^{2} \cdot \mathrm{h} \cdot \mathrm{kPa}$ reported by Miranda et al. [11]. However, despite the WVP values reported for chitosan films, a comparison between data is inaccurate because the permeability of the hydrophilic films is directly related to the interval of $\mathrm{RH}$, film thickness and the method employed [11]. Another factor that influences the WVP is the addition of plasticizers that generally favors the migration of water molecules [12]. However, no significant differences were found on WVP with the inclusion of PSI in our ChLA-TSA films (Table 1).

Table 1. Experimental data for chitosan and chitosan-grafted LA.

\begin{tabular}{|c|c|c|c|c|}
\hline Material & Yield (\%) & Degree of Grafting (\%) & Film Thickness (mm) & $\mathrm{VWP}\left(\mathrm{g} \cdot \mathrm{mm} / \mathrm{m}^{2} \cdot \mathrm{h} \cdot \mathrm{kPa}\right)$ \\
\hline $\mathrm{Ch}$ & - & - & $0.062 \pm 0.006^{\mathrm{b}}$ & $7 \times 10^{-} 2 \pm 2 \times 10^{-3 a}$ \\
\hline ChLA & $51.16 \pm 1.96^{\mathrm{a}}$ & $36.85 \pm 2.33^{b}$ & $0.074 \pm 0.003^{b}$ & $1.6 \times 10^{-3} \pm 2.6 \times 10^{-4 b}$ \\
\hline ChLA-TSA & $58.77 \pm 1.65^{\mathrm{a}}$ & $43.62 \pm 0.90^{a}$ & $0.15 \pm 0.003^{\mathrm{a}}$ & $4.2 \times 10^{-5} \pm 1.4 \times 10^{-6 c}$ \\
\hline ChLA-TSA-SPI & $48.45 \pm 0.58^{a}$ & $33.38 \pm 0.80^{b}$ & $0.15 \pm 0.021^{\mathrm{a}}$ & $4.4 \times 10^{-5} \pm 3.1 \times 10^{-6 c}$ \\
\hline LDPE & - & - & $2.07 \pm 0.3^{c}$ & $7.6 \times 10^{-10} \pm 1.4 \times 10^{-9 d}$ \\
\hline
\end{tabular}

Data are shown as the average of four determinations with their corresponding standard deviation. Values in a column with the same letter are not significantly different at $p<0.05$ determined by multiple comparisons of means by Tukey-Kramer test.

The characterization of the obtained chitosan gave an $M_{\mathrm{v}}$ of $274.8 \pm 5 \mathrm{kDa}$, ash content of $1 \pm 0.05$ and a DA of $6.43 \pm 0.19$ for this polymer. The FT-IR spectrum of the grafted chitosan shows the characteristic signals for chitosan and that at $c a .1700 \mathrm{~cm}^{-1}$ assigned to the carbonyl moiety of LA [13,14] (see the Supplementary Data file for the FTIR spectra of chitosan and grafted chitosan samples). The ${ }^{1} \mathrm{H}-\mathrm{NMR}$ spectra of the $\mathrm{Ch}$ and grafted sample ChLA-TSA (Table 1) film are shown in Figure 1 (bottom spectrum) and Figure 1 (top spectrum), respectively, with the assigned signals. 


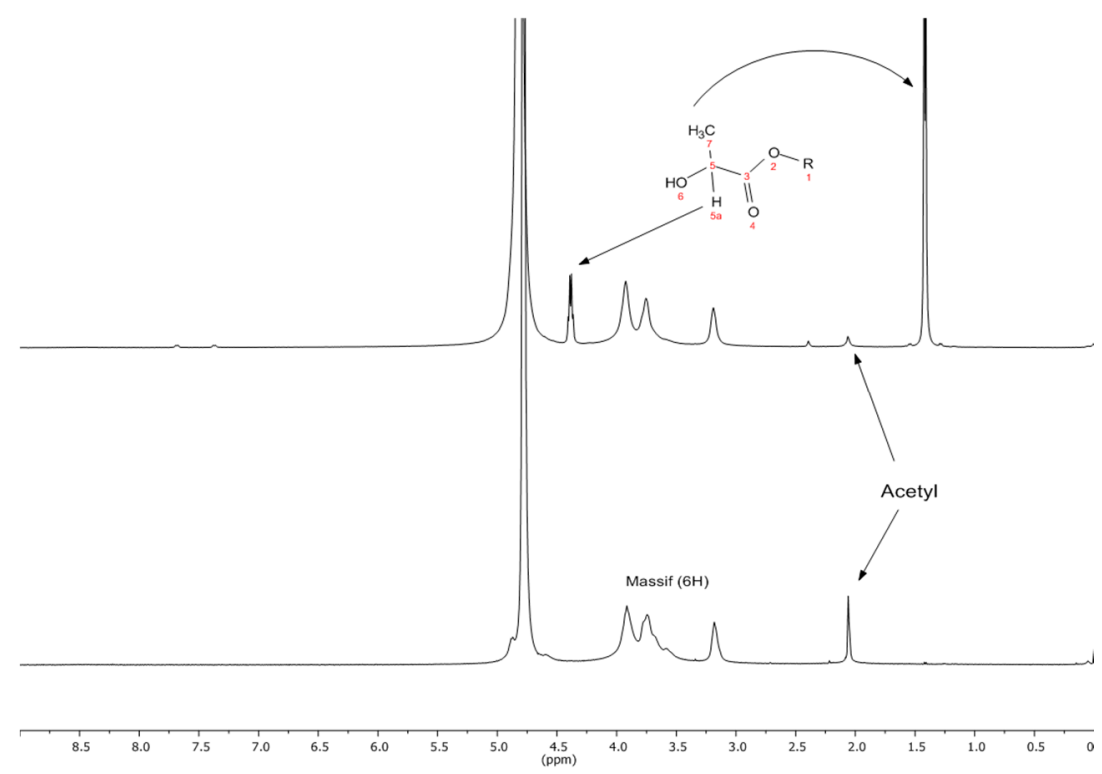

Figure 1. ${ }^{1} \mathrm{H}-\mathrm{NMR}$ spectra of $\mathrm{Ch}$ (bottom) and ChLA-TSA (top).

\subsection{Mechanical Properties of Films}

The mechanical properties in films are shown in Table 2, where is clearly demonstrated that the flexibility of the grafted materials was improved compared to that of $\mathrm{Ch}$ films. The decrease of the Young's modulus indicates that the film is less rigid and possesses an enhanced capacity for elongation, which is an interesting feature for some applications. In general, the mechanical properties on chitosan-based films are affected by the chitin source, film thickness, DA and $M_{\mathrm{V}}$ of the chitosan, the use of plasticizers as well as the initial chitosan acid solution [15]. Several studies suggest that the films prepared with acetic acid are stiffer owing to the existence of relatively strong intermolecular interactions than those formed with citric acid [16]. In addition, grafting can also affect the mechanical properties.

Table 2. Mechanical properties of the prepared films.

\begin{tabular}{cccc}
\hline Material & Young's Modulus (MPa) & Elongation at Break (\%) & Tensile Strength (MPa) \\
\hline Ch & $2.2 \pm 0.56^{\mathrm{d}}$ & $57.2 \pm 27.0^{\mathrm{b}}$ & $0.61 \pm 0.20^{\mathrm{c}}$ \\
ChLA & $16.8 \pm 0.20^{\mathrm{c}}$ & $75.4 \pm 5.9^{\mathrm{b}}$ & $31.3 \pm 1.12^{\mathrm{b}}$ \\
ChLA-TSA & $105.6 \pm 2.15^{\mathrm{b}}$ & $67.6 \pm 5.6^{\mathrm{b}}$ & $19.25 \pm 1.19^{\mathrm{b}}$ \\
ChLA-TSA-SPI & $49.26 \pm 7.43^{\mathrm{c}}$ & $78.0 \pm 9.5^{\mathrm{b}}$ & $88.29 \pm 2.46^{\mathrm{a}}$ \\
LDPE & $371.62 \pm 12.48^{\mathrm{a}}$ & $205 \pm 24.4^{\mathrm{a}}$ & $23.58 \pm 0.96^{\mathrm{b}}$ \\
\hline
\end{tabular}

Data are shown as the average of four determinations with their corresponding standard deviation. Values in a column with the same letter are not significantly different at $p<0.05$ determined by multiple comparisons of means by Tukey-Kramer test.

\subsection{Analyzes of Fresh Cheese Inoculated with L. monocytogenes}

The initial moisture of samples was about $45 \%$ and its decrease was near $5 \%$ for the control sample after 14 days (Figure 2D). All samples displayed a considerable moisture loss but the LDPE packaging exhibited the lowest (20\%) after 14 days in a statistically different group. This behavior is attributed to low moisture transfer and small VWP of the LDPE film. In addtion, after 14 days of storage, the control and grafted cheeses show significant differences in moisture content. Noteworthily, the inoculation procedure required that cheese samples remain for $1 \mathrm{~h}$ in a laminar flow hood under ambient aseptic conditions which might favor the draining of serum. 

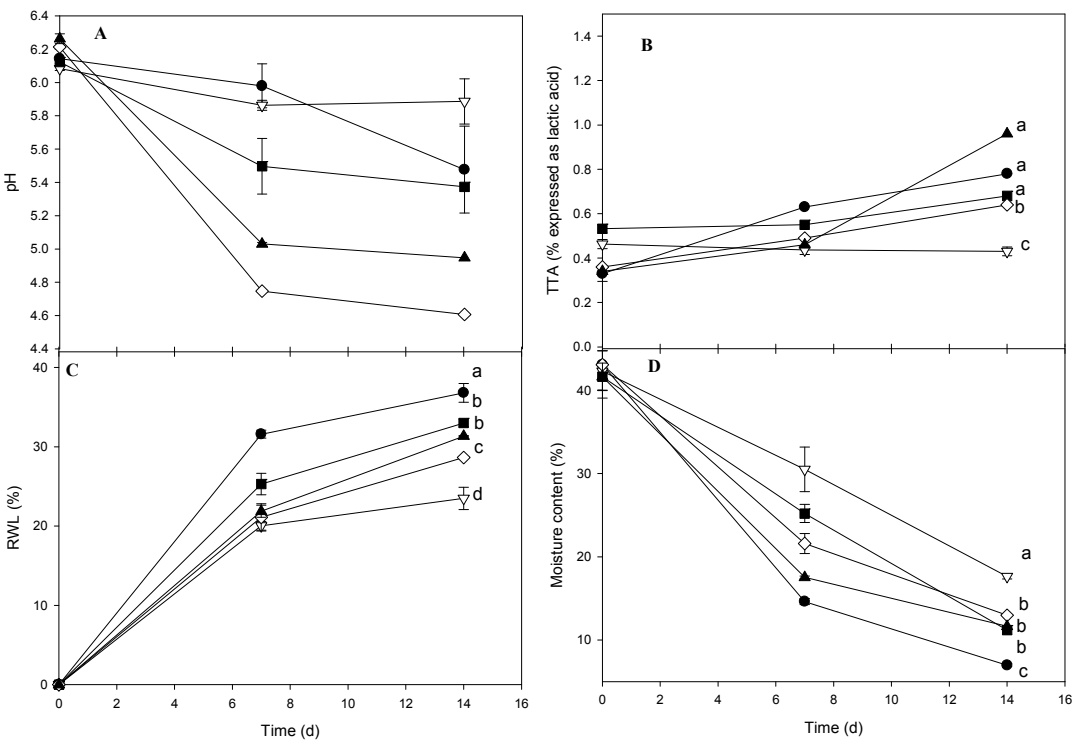

Figure 2. Time course of pH (A); TTA (B); RWL (C) and moisture content (D) of chesses inoculated with L. monocytogenes stored at $4{ }^{\circ} \mathrm{C}$ and $22 \% \mathrm{RH}$ coated with different materials. Control (uncoated) $(\bullet)$; LDPE $(\nabla)$; ChLA $(\mathbf{\square})$; ChLA-TSA $(\diamond)$ and ChLA-TSA-SPI $(\boldsymbol{\Delta})$. Data are the average of three determinations. Plots with the same letter in a graph are not significantly different at $p<0.05$ as determined by multiple comparisons of means by the Tukey-Kramer test. Continuous lines are included only as a visual guide.

In regard to RWL (Figure 2C), significant differences among treatments were also observed. Cheese packed in LDPE had the lowest value $(0.5 \% \pm 0.8 \%)$ while the control sample displayed the poorest results. Samples wrapped with ChLA-TSA film showed the best results among the biodegradable packaging examined with statistically less RWL than that with ChLA. This experimental result might be attributed to the highest presence of grafted LA in the ChLA-TSA material. Nonetheless, the low RWL in the LDPE sample [17] compared with chitosan-based materials was expected owing to the WVP values as well as the relatively high RWL (40\%) in the control after 14 days of storage. The $\mathrm{pH}$ of cheeses infected with L. monocytogenes tends to decrease during storage for all package types, although this was less noticeable for LDPE followed by the control samples (Figure 2A). The LDPE and control packages showed a significant difference from all other experimental results. The $\mathrm{pH}$ for LDPE was about 6 and remained nearly constant from day 7 to 14 owing to the reduced migration of acids throughout the film. Notably, ChLA-TSA packaging showed the lowest $\mathrm{pH}$ values after 14 days notwithstanding the observed TTA increase (Figure 2B). In this regard, Martins et al. [18] compared the $\mathrm{pH}$ of Ricotta cheese inoculated with L. monocytogenes and coated with galactomannans containing nisin to demonstrate that coated cheeses had lower $\mathrm{pH}$ values at the end of storage than that of control without coating. The authors attributed this behavior in the control due to the release of alkaline components generated during protein degradation by surface microorganisms. However, we did not observed a $\mathrm{pH}$ decrease under any condition, thereby proteolytic activities might be ruled out in our study. After 14 days of storage, the TTA of coated cheeses with ChLA-TSA-SPI exhibited a significant increase from ca. 0.35 to near 1 (Figure 2B). This increase might be ascribed to a favored LA migration. Statistical analysis however, shows no significant differences in the TTA for ChLA-TSA-SPI, control and ChLA but for ChLA-TSA. Therefore, the experimental results evidenced that the presence of the plasticizer did not affect LA migration significantly. Worth of note, LDPE packaging tend to decrease the TTA of cheese samples thorough the storage. On the other hand, the TTA increase measured in the control, which is remarkable from 7 to 14 days, might indicate the formation of LA due to the lactose fermentation by lactic acid bacteria (LAB). In regard to the microbiological analysis, there was no microbial count of L. monocytogenes in the non-inoculated cheeses. On the other hand, the concentration 
of L. monocytogenes in inoculated cheese was $1 \times 10^{4} \mathrm{CFU} / \mathrm{mL}$, however, no growth was observed during the first 7 days. Lactic bacteria might possess the ability to inhibit this microorganism due to the decrease in $\mathrm{pH}$ owing to the production of lactic acid or due to competition for utilization of carbohydrates in the substrate that leads to decrease the common specific nutrients of L. monocytogenes. In addition, lactic acid bacteria's ability to produce inhibitory compounds such as hydrogen peroxide, bacteriocins and bacteriocin-like substances is well known [18]. Nonetheless, after 14 days of storage we observed characteristic L. monocytogenes colonies in LDPE coated and control samples (Figure 3). Our results suggest that the coated cheeses with chitosan-based packaging have the lowest bacterial count significant differences with respect to the control and LDPE samples. Interestingly, the samples coated with ChLA-TSA and ChLA-TSA-SPI showed complete inhibition of L. monocytogenes after 7 days of storage and this was statistically different from the result of ChLA. The loss of moisture and the decreased water activity $\left(\mathrm{a}_{\mathrm{w}}\right)$ could limit the growth of L. monocytogenes, for which the minimum $\mathrm{a}_{\mathrm{w}}$ for growth is 0.92 [19]. Nonetheless, despite the significant differences in the measured moisture (Figure 2D) between the uncoated control and coated cheeses (Figure 2), there is a conclusive evidence of the pathogen depletion by the grafted chitosan films (Figure 3). In the aforementioned study by Martins et al. [18], the growth of Listeria monocytogenes in Ricotta cheese using galactomannan with added nisin was $4.5 \log$ CFU/g after 15 days of storage. This value means less inhibition of this pathogen than the measured in our fresh cheese using grafted chitosan packaging (Figure 3).

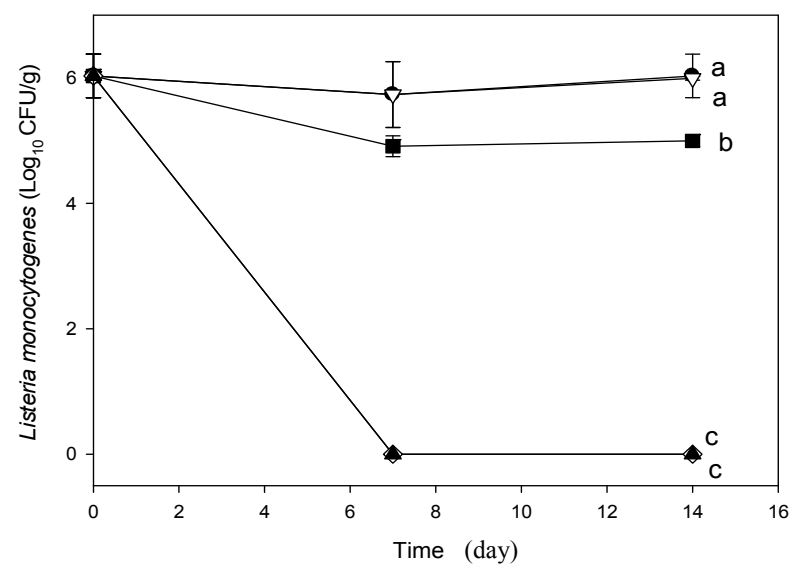

Figure 3. Time course of plate count with Oxford agar of L. monocytogenes in cheese at $4{ }^{\circ} \mathrm{C}$ and $22 \% \mathrm{RH}$. Symbols: Control (uncoated) $(\bullet)$; LDPE $(\nabla)$; ChLA $(\boldsymbol{\square})$; ChLA-TSA $(\diamond)$ and ChLA-TSA-SPI $(\boldsymbol{\Delta})$ Data are the average of three determinations. Plots with the same letter in the graph are not significantly different at $p<0.05$ as determined by multiple comparisons of means of microbial counts between materials by Tukey-Kramer test.

\subsection{SEM Analyses of Samples}

Figure 4 shows SEM micrographs of coated cheese samples that were not inoculated with L. monocytogenes after 14 days of storage. Figure $4 \mathrm{~A}$ corresponds to the uncoated control, in which a segment of hyphae and spores are observed due to fungal growth, as well as yeast proliferation. These observations are well related with the high count $(9.3 \log \mathrm{CFU} / \mathrm{g}$ ) of fungi and yeast seen in this study in potato dextrose agar. Several fungi and yeasts of the genera Penicillium sp., Cladosporium sp. and Geotrichum candidum have been identified in Mexican fresh cheeses and in the case of yeast the presence of Candida guilliermondii, Candida lipolytica and Candida tropicalis has been detected [20]. 


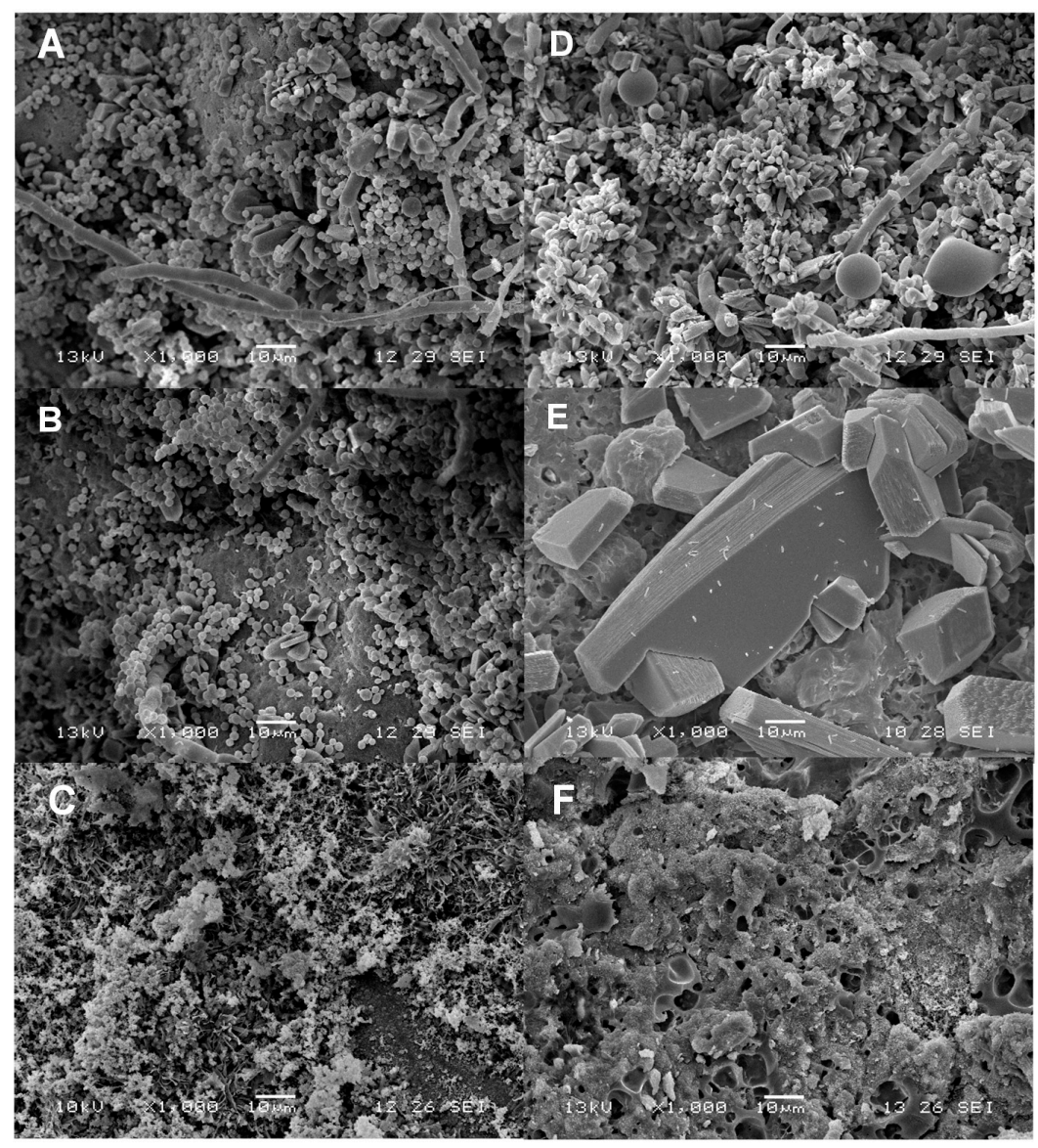

Figure 4. SEM micrographs of fresh cheese samples non-inoculated:control non-packaged (A); LDPE packaging (B); ChLA-TSA-SPI packaging(C); Inoculated with L. monocytogenes control non-packaged (D); LDPE packaging (E) and ChLA-TSA-SPI packaging (F).

The non-inoculated cheeses packed in LDPE are shown in Figure 4B where it is seen that this material displayed low yeast inhibition effectiveness. The growth of filamentous fungi is evident in addition to rod-shaped bacteria. Contrarily, SEM micrographs of samples of cheeses packaged with grafted ChLA-TSA-SPI, shown in Figure 4C, display a considerable reduction of microorganisms and hyphae and spores and yeast are not observed. The spongy complex formed by agglomeration of spherical particles might correspond to casein micelles. They are reported to display spongy and porous structures with diameters between 30 and $300 \mathrm{~nm}$ [21]. Figure 4D-F correspond to the SEM of inoculated cheese samples with L. monocytogenes (see the Supplementary Data for SEM images of L. monocytogenes). The SEM for inoculated cheese control samples show a segment of hyphae and fat globules (Figure 4D). Fat globules of milk have a diameter ranging up to $2-6 \mu \mathrm{m}$ thus being 25 times larger than the average diameter of casein micelles [21], which is consistent with our SEM images of fresh cheeses. The presence of short rods and bacilli, both less than $5 \mu \mathrm{m}$ in size, are observed with shaped sheet structures in Figure 4E for LDPE coated samples. These crystals might be attributed to lactose, in agreement with SEM studies conducted by Kougoulos et al. using anti-solvent crystallization techniques [22]. In addition, spongy and porous structures corresponding to the casein micelles are present.

Remarkably, bacteria are also observed as short rods with morphology similar to L. monocytogenes in the inoculated cheeses in Figure 4D,E. On the other hand, Figure 4F shows inoculated cheeses coated with ChLA-TSA-SPI, which was found free of visible microorganisms. Noteworthily, the presence of lactose crystals and also shrunk casein micelles is also observed in cheese samples coated with the chitosan-based material without bacterial inoculation (Figure 4C). In this regard, Martin et al. [21] 
reported casein micelle distortion as a consequence of the drying step during SEM sample preparation. In some samples (Figure $4 \mathrm{~F}$ ) differences in morphology are observed, which might be due to interactions between aggregates of casein and chitosan. In this regard, it has been documented that casein and chitosan can interact to form soluble or insoluble complexes following Maillard reaction or ionic interactions, which has found several applications including drug delivery [23].

\section{Materials and Methods}

\subsection{Materials}

Chitosan was obtained by heterogeneous deacetylation of chitin extracted from the lactic acid fermentation (LAF) of shrimp (Litopenaeus vanameii) wastes and purified as reported elsewhere [10]. LA (85\% aqueous solution) was acquired from J.T. Baker (Toluca, Mexico). Triethanolamine (TEA) and p-toluenesulfonic acid (TSA) was supplied by Sigma-Aldrich (Saint Louis, MO, USA). Low-density polyethylene (LDPE) film samples were kindly donated by Casa Miyako (Mexico City, Mexico). The L. monocytogenes strain was a kind gift of Dr. Rigoberto Hernández-Castro from the culture collection of Hospital General Dr. Manuel Gea González (Mexico City, Mexico) and in trypticaseine soy broth (TSB) at $37^{\circ} \mathrm{C}$ for $24 \mathrm{~h}$ to attain $10^{7}$ colony-forming units (CFU) per mL. Inoculum was prepared by dilution in sterile saline solution $\left(0.9 \mathrm{NaCl} w t / v \%\right.$ (weight/volume) ) up to $10^{4} \mathrm{CFU} / \mathrm{mL}$. Soy protein isolate (SPI) was purchased to Sigma Aldrich. Fresh cheeses were provided by a farm (Celaya Guanajuato, Mexico).

\subsection{Preparation of Chitosan Films}

Chitosan was dissolved (1.15 wt/v\%) in acetic acid (0.1 M) under continuous agitation for $24 \mathrm{~h}$ at ambient temperature. Solutions were filtered through a metallic sieve (mesh No. 100) to remove insoluble matter. Individual chitosan films (Ch) were obtained by casting as follows: $30 \mathrm{~g}$ of the chitosan solution were poured into polystyrene (PS) Petri dishes and dried in an oven at $60{ }^{\circ} \mathrm{C}$ for $24 \mathrm{~h}$.

\subsection{Grafting of Chitosan with LA and Production Films}

The grafting of chitosan with LA was conducted following the method reported by Albertsson and co-workers [13] with some modifications. In a typical experiment, $40 \mathrm{~mL}$ of a chitosan (1 g) solution in LA $(0.5 \mathrm{M})$ was mixed with $160 \mathrm{~mL}$ of LA $(0.3 \mathrm{M})$ containing TSA $(1 \% w / w)$ and heated at $80{ }^{\circ} \mathrm{C}$ for $2 \mathrm{~h}$ under inert atmosphere. Then, solutions were poured into PS Petri dishes, placed in an oven $\left(80^{\circ} \mathrm{C}\right)$ under vacuum for $3 \mathrm{~h}$ and further dried at atmospheric pressure for $6 \mathrm{~h}$ at $60{ }^{\circ} \mathrm{C}$ to give film samples (ChLA-TSA). The non-reacted LA in the resulting films was removed by Soxhlet extraction using acetone for $18 \mathrm{~h}$. In another formulation, SPI aqueous solution $(0.25 w t / v \%)$ was added at $25^{\circ} \mathrm{C}$ to the grafted chitosan after the casting procedure. Then, the ChLA-TSA-SPI films were obtained by casting $50 \mathrm{~g}$ of the solution onto PS Petri dishes placed in an oven at $60^{\circ} \mathrm{C}$ for $24 \mathrm{~h}$ [24]. Blank experiments were conducted using identical procedure without the TSA addition to obtain the ChLA samples.

\subsection{Chitosan Characterization and Characterization of Films}

The $M_{\mathrm{v}}$ of chitosan, dissolved in acetic acid $(0.3 \mathrm{M})$ and sodium acetate $(0.2 \mathrm{M})$ at $25{ }^{\circ} \mathrm{C}$ [25], was determined from time flow measurements in an Oswald glass capillary viscometer using the Mark-Houwink-Kuhn-Sakurada equation with $\alpha=0.85$ and $K=1.38 \times 10^{-5} \mathrm{~L} / \mathrm{g}$. Degree of acetylation (DA) was determined by integration of characteristic signals in the ${ }^{1} \mathrm{H}-\mathrm{NMR}$ spectra recorded in $\mathrm{D}_{2} \mathrm{O}$ with $10 \% \mathrm{HCl}$ in a spectrometer (AVANCE-III 500, Bruker, Rheinstetten, Germany) [14,25]. The degree of grafting percentage (DG\%) was calculated according to Equation (1):

$$
\operatorname{DG}(\%)=\left(\frac{100\left(W_{2}-W_{1}\right)}{W_{1}}\right)
$$


where $W_{1}$ and $W_{2}$ are the weights of the materials on a dry basis before and after the grafting procedure, respectively.

Infrared spectra were acquired in an ATR-FTIR apparatus (Perkin Elmer 100, Waltham, MA, USA). Mechanical properties upon extension were determined according to ASTM D882-97 [26] in a mechanical testing machine (SINTECH 1/S, MTS, Eden Prairie, MN, USA) with a load cell of $100 \mathrm{~N}$. Samples were conditioned to $44 \%$ relative humidity (RH) at $25{ }^{\circ} \mathrm{C}$ prior to analyses. Water vapor permeability (WVP) was determined at $4{ }^{\circ} \mathrm{C}$ using a modification of the ASTM method [27]. Films were cut to a diameter of $2 \mathrm{~cm}$ and then fixed to permeability cells. Storage conditions of fresh cheese were simulated within an interval of $22 \%-75 \% \mathrm{RH}$. The cell with an $\mathrm{RH}$ of $75 \%$ was prepared with a saturated solution of $\mathrm{NaCl}$ and the $\mathrm{RH}$ in the chamber was $22 \%$ by a saturated solution of $\mathrm{KCH}_{3} \mathrm{CO}_{2}$. Determinations were conducted by triplicate. Determination of film thickness was conducted by six random measurements to each sample with a digital micrometer (Mitutoyo 1D-C112E, Kanagawa, Japan).

\subsection{Analysis of Coated Cheese Samples}

L. monocytogenes inoculum $(35 \mathrm{~mL})$ with $10^{4} \mathrm{CFU} / \mathrm{mL}$ was poured onto a sterile wooden board of $1050 \mathrm{~cm}^{2}$ surface previously sterilized in an autoclave [3]. Cheese samples were placed on the inoculated board for $30 \mathrm{~min}$. Then, the inoculation procedure was repeated with an additional $35 \mathrm{~mL}$ of $L$. monocytogenes suspension and the cheese samples were put on their non-inoculated sides for $30 \mathrm{~min}$. The inoculated cheese samples were coated with the chitosan-based materials and LDPE. Films were heat sealed using gelatin as a sealing lacquer. The inoculation procedure and coating of samples were carried out under aseptic conditions using a biological safety cabinet. Control and cheeses coated with films were stored at $22 \% \mathrm{RH}$ and $4{ }^{\circ} \mathrm{C}$.

For weight loss determinations, samples of cheese coated with films and that for control were weighed daily. The slope of the weight loss vs. time plot was divided by the exposed film area to calculate the water vapor transmission rate. Relative weight loss (RWL) in cheese samples was determined by measuring the weight of samples at the beginning $\left(W_{\mathrm{I}}\right)$ and after 7 and 15 days of storage $\left(W_{\mathrm{F}}\right)$ using Equation (2):

$$
R W L=\frac{\left(W_{I}-W_{F}\right)}{W_{I}} \times 100
$$

For $\mathrm{pH}$ and acidity determinations, cheese samples were unpacked every 7 days, then $10 \mathrm{~g}$ were suspended in $100 \mathrm{~mL}$ of distilled water and mixed during $2 \mathrm{~min}$ in a homogenizer (Sper Scientific 460003 , St. Louis, MO, USA). Suspensions were filtered, and supernatants analyzed to determine total acidity (TTA) by potentiometric titration using $0.1 \mathrm{~N} \mathrm{NaOH}$. Results were expressed as lactic acid percentage. The $\mathrm{pH}$ measurements were carried out in a digital potentiometer (Hanna Instruments Digital, Padova, Italy). Moisture content was determined in a thermobalance (Wiggen Hauser, Berlin, Germany) at $80^{\circ} \mathrm{C}$ using $1 \mathrm{~g}$ of material. L. monocytogenes enumeration was carried out by inoculation of decimal dilutions in peptone water on Oxford agar base plates and incubation at $30^{\circ} \mathrm{C}$ for $48 \mathrm{~h}$. The black colonies were counted and expressed as $\log _{10} \mathrm{CFU} / \mathrm{g}$. For yeasts and molds enumeration, serial dilutions were prepared in sterile saline solution and inoculated on plates of potato dextrose agar acidified with tartaric acid. Determinations were done by triplicate.

\subsection{Scanning Electron Microscopy Analyses}

Square $(0.5 \mathrm{~cm} \times 0.5 \mathrm{~cm})$ samples from the surface of the cheeses were fixed with $5 \%(v / v)$ glutaraldehyde and stored for $24 \mathrm{~h}$ at $4{ }^{\circ} \mathrm{C}$. Samples were washed with phosphate buffer $(0.1 \mathrm{M} \mathrm{pH} 7)$ and subsequently treated with $1 \%(w / v) \mathrm{OsO}_{4}$ for $2 \mathrm{~h}$. Then, samples were dehydrated with alcohol and sputtered with carbon and gold for examination in a scanning electron microscope (JEOL JSM-5900 LV, Tokyo, Japan). 


\subsection{Statistical Analysis}

A randomized design was carried out in triplicate for experiments with chitosan-based packaging materials and LDPE. NCSS 2000 software (NCSS Inc., Kaysville, UT, USA) computed the analysis of variance with yield, degree of grafting, film thickness, WVP, mechanical properties, RWL, moisture content, $\mathrm{pH}$, TTA and L. monocytogenes counts as response variables. Means were compared with Tukey-Kramer multiple means comparison test $(p<0.05)$.

\section{Conclusions}

This work demonstrates that the use of non-toxic chitosan-g-LA for packaging of fresh cheese offers an alternative for the preservation of the quality of this product during storage and increased shelf life and more importantly it inhibits the growth of Listeria monocytogenes, which is considered a very dangerous human food pathogen. Our chitosan-based material displayed a remarkable improvement compared to non-coated cheeses as well as LDPE coated samples, which represents an ecological advance for reduction of non-degradable oil-derived material use. Additionally, the chitosan grafted with LA displays improved mechanical properties as compared to native chitosan.

Supplementary Materials: Supplementary materials can be accessed at: http://www.mdpi.com/1420-3049/ $21 / 4 / 469 / \mathrm{s} 1$.

Acknowledgments: The authors would like to thank Secretaría de Ciencia, Tecnología e Innovación del Distrito Federal (SECITI) (Project No. PICSO12-152) for funding and CONACyT for grant (MLC and LSH). Thanks are also due to Mariana Ramírez-Gilly for her assistance with mechanical tests.

Author Contributions: K.S. conceived and designed the main ideas of this paper, analyzed the experimental results, and wrote the paper. M.L. and L.N.S. carried out the experiments and wrote the paper. E.M.D. and A.E. participated in materials preparation. A.T. participated and guided the mechanical properties determinations. M.G. revised this paper and guided the writing of this paper. The authors read and approved the final manuscript.

Conflicts of Interest: The authors declare no conflict of interest.

\section{References}

1. Ferreira, V.; Wiedmann, M.; Teixeira, P.; Stasiewicz, M.J. Listeria monocytogenes persistence in food-associated environments: Epidemiology, strain characteristics, and implications for public health. J. Food Protect. 2014, 1, 150-170. [CrossRef] [PubMed]

2. Farber, J.M.; Peterkin, P.I. Listeria monocytogenes, a food-borne pathogen. Microbiol. Rev. 1991, 55, 476-511. [PubMed]

3. Genigeorgis, C.; Carniciu, M.; Dutulescu, D.; Farver, T.B. Growth and survival of Listeria monocytogenes in market cheeses stored at 4 to $30^{\circ} \mathrm{C}$. J. Food Protect. 1991, 54, 662-668.

4. Stessl, B.; Fricker, M.; Fox, E.; Karpiskova, R.; Demnerova, K.; Jordan, K.; Ehling-Schulz, M.; Wagner, M. Collaborative survey on the colonization of different types of cheese-processing facilities with Listeria monocytogenes. Foodborne Pathog. Dis. 2013, 11, 8-14. [CrossRef] [PubMed]

5. Melo, J.; Andrew, P.W.; Faleiro, M.L. Listeria monocytogenes in cheese and the dairy environment remains a food safety challenge: The role of stress responses. Food Res. Int. 2015, 67, 75-90. [CrossRef]

6. Tenenhaus-Aziza, F.; Daudin, J.J.; Maffre, A.; Sanaa, M. Risk-based approach for microbiological food safety management in the dairy industry: The case of Listeria monocytogenes in soft cheese made from pasteurized milk. Risk Anal. 2014, 34, 56-74. [CrossRef] [PubMed]

7. Torres-Vitela, M.R.; Mendoza-Bernardo, M.; Castro-Rosas, J.; Gomez-Aldapa, C.A.; Garay-Martínez, L.E.; Navarro-Hidalgo, V.; Villarruel-López, A. Incidence of Salmonella, Listeria monocytogenes, Escherichia coli O157:H7, and staphylococcal enterotoxin in two types of Mexican fresh cheeses. J. Food Protect. 2012, 75, 79-84. [CrossRef] [PubMed]

8. Cruz-Romero, M.C.; Murphy, T.; Morris, M.; Cummins, E.; Kerry, J.P. Antimicrobial activity of chitosan, organic acids and nano-sized solubilisates for potential use in smart antimicrobially-active packaging for potential food applications. Food Control 2013, 34, 393-397. [CrossRef]

9. Suyatma, N.; Copinet, A.; Copinet, E.; Fricoteaux, F.; Coma, V. Different Pla grafting techniques on chitosan. J. Polym. Environ. 2011, 19, 166-171. [CrossRef] 
10. Di Pierro, P.; Sorrentino, A.; Mariniello, A.; Concetta, V. Chitosan/whey protein as active coating to extend Ricotta cheese shelf-life. Food Sci. Technol. 2011, 44, 2224-2327. [CrossRef]

11. Miranda, P.; Cardenas, G.; Lopez, D.; Sagahon, A. Comportamiento de peliculas de quitosano compuesto en un modelo de almacenamiento de aguacate. J. Mex. Chem. Soc. 2003, 47, 1456-1467.

12. Leceta, I.; Guerrero, P.; de la Caba, K. Functional properties of chitosan-based films. Carbohydr. Polym. 2013, 93, 339-346. [CrossRef] [PubMed]

13. Qu, X.; Wirsén, A.; Albertsson, A. Synthesis and characterization of $\mathrm{pH}$-sensitive hydrogels based on chitosan and D,L-lactic acid. J. Appl. Polym. Sci. 1999, 74, 3193-3202. [CrossRef]

14. Hirai, A.; Odani, H.; Nakajima, A. Determination of degree of deacetylation of chitosan by ${ }^{1} \mathrm{H}$ NMR spectroscopy. Polym. Bull. 1991, 26, 87-94. [CrossRef]

15. Khoshgozaran, S.; Hossain-Azizi, M.H.; Hamidy, Z.; Bagheripoor-Fallah, F. Mechanical, physicochemical and color properties of chitosan based-films as a function of Aloe vera gel incorporation. Carbohydr. Polym. 2012, 87, 2058-2062. [CrossRef]

16. Bonilla, J.; Fortunati, E.; Vargas, M.; Chiralt, A.; Kenny, J.M. Effects of chitosan on the physicochemical and antimicrobial properties of PLA films. J. Food Eng. 2013, 119, 236-243. [CrossRef]

17. Han, H. Innovations in Food Packaging. J. Food Sci. Technol. 2010, 47, 1765-1770.

18. Martins, J.; Cerqueira, M.; Souza, B.; Carmo, A.; Vicente, A. Shelf Life extension of Ricotta cheese using coatings of galactomannans from nonconventional sources incorporating nisin against Listeria monocytogenes. J. Agric. Food Chem. 2010, 58, 69-74. [CrossRef] [PubMed]

19. Mariani, C.; Oulahal, N.; Chamba, J.; Dubois-Brissonnet, F.; Notz, E.; Briandet, R. Inhibition of Listeria monocytogenes by resident biofilms present on wooden shelves used for cheese ripening. Food Control 2011, 22, 45-51. [CrossRef]

20. Saxer, S.; Schwenninger, S.M.; Lacroix, C. Characterization of the microflora of industrial Mexican cheeses produced without added chemical preservatives. LWT Food Sci. Technol. 2013, 53, 314-320. [CrossRef]

21. Martin, A.H.; Goff, H.D.; Smith, A.; Dalgleish, D.G. Immobilization of casein micelles for probing their structure and interactions with polysaccharides using scanning electron microscopy (SEM). Food Hydrocolloid 2006, 20, 817-824. [CrossRef]

22. Kougoulos, E.; Marziano, I.; Miller, P.R. Lactose particle engineering: Influence of ultrasound and anti-solvent on crystal habit and particle size. J. Cryst. Growth 2010, 312, 3509-3520. [CrossRef]

23. Razmi, M.; Divsalara, A.; Saboury, A.A.; Izadi, Z.; Haertlé, T.; Mansuri-Torshizidi, H. $\beta$-casein and its complexes with chitosan as nanovehicles for delivery of a platinum anticancer drug. Colloids Surfaces B 2013, 112, 362-367. [CrossRef] [PubMed]

24. Espadín, A.; Vázquez, N.; Tecante, A.; Tamay de Dios, L.; Gimeno, M.; Velasquillo, C.; Shirai, K. Fibroblast viability and inhibitory activity against Pseudomonas aeruginosa in lactic acid-grafted chitosan hydrogels. J. Appl. Polym. Sci. 2014, 131, 14. [CrossRef]

25. Pacheco, N.; Gárnica-González, M.; Gimeno, M.; Bárzana, E.; Trombotto, S.; David, L.; Shirai, K. Structural characterization of chitin and chitosan obtained by biological and chemical methods. Biomacromolecules 2011, 12, 3285-3290. [CrossRef] [PubMed]

26. American Society for Testing and Materials. Standard test method for tensile properties of thin plastic sheeting. In Standards Designations: D882-02. Annual Book of ASTM Standards; ASTM D882-02; American Society for Testing and Materials: Philadelphia, PA, USA, 1991; pp. 194-202.

27. American Society for Testing and Materials. Standard test methods for water vapour transmission of materials. In Standards Designations: E96-95. Annual Book of ASTM Standards; ASTM E96-95; American Society for Testing and Materials: Philadelphia, PA, USA, 1995; pp. 406-413.

Sample Availability: Samples of the compounds are not available from the authors.

(C) 2016 by the authors; licensee MDPI, Basel, Switzerland. This article is an open access article distributed under the terms and conditions of the Creative Commons Attribution (CC-BY) license (http:/ / creativecommons.org/licenses/by/4.0/). 